\section{Math Counts}

\section{Too!}

\section{Promoting Family Engagement in}

Math Activities at Home

Erica L. Zippert, Betsy Diamante-Cohen, and Annette Y. Goldsmith
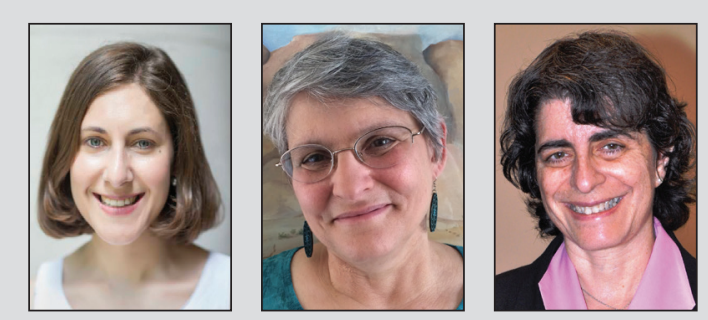

Erica Zippert is a postdoctoral scholar at Vanderbilt University in Nashville, Tennessee. Her research involves studying preschool children's mathematical thinking and how it can be supported in the context of informal learning activities with parents and peers. Betsy Diamant-Cohen is an early literacy trainer and Executive Director of Mother Goose on the Loose, Baltimore, Maryland. Annette Y. Goldsmith is a lecturer at the University of Washington Information School who teaches online from her home in Los Angeles, California.
A lthough librarians typically focus on language and literacy when planning children's programs, research suggests that math skills are valuable too. Today, proficiency in math is an essential professional skill. Many careers involve math, and math classes act as gateways to attaining degrees in STEM fields. ${ }^{1}$ In our personal lives, math is used daily to manage household finances and make informed decisions about our health. ${ }^{2}$ Finally, math skills at school entry are strong predictors of later academic achievement in both math and reading. ${ }^{3}$ Therefore, math development should be considered an important part of children's school readiness skills.

Evidence suggests that parents and other adults can make a positive impact on children's math learning by guiding them to talk about and explore early math concepts. ${ }^{4}$ However, parents from a range of socioeconomic backgrounds report supporting their children's language and literacy skills more often than math skills at home, ${ }^{5}$ and low-income children receive even less math-specific input from parents than their more affluent peers. ${ }^{6}$ Thus, it is important for children's librarians to encourage all parents to support their children's math skills at home.

\section{Why Are Early Math Experiences Important?}

Research shows that early math experiences are essential for developing number knowledge, which serves as the cornerstone for mathematical thinking. An observational study assessed how parents with infants talked about numbers by recording interactions at home over several time points. ${ }^{7}$ The researchers found that talk about numbers varied substantially from parent to parent, but this talk predicted children's numerical knowledge as preschoolers. Additionally, more parent talk about numbers describing visible sets of objects was most predictive of children's later number knowledge. ${ }^{8}$ This is because children need help understanding that number words do not just appear in the counting string, but also represent specific numbers of countable objects. Ultimately, this talk helped children to understand that number words are not just words, but represent actual objects that can be counted.

Other researchers compared different ways of supporting preschool children's number knowledge. ${ }^{9}$ They confirmed that counting and labeling visible sets of objects was more successful in improving preschool children's number knowledge than only labeling quantities or only counting them. Thus, discussing numbers by counting and labeling objects (e.g., toys in the play area and chairs at the dinner table) seems crucial in supporting young children's developing numerical knowledge, particularly to help them understand what numbers mean.

\section{What Could These Experiences Look Like?}

Other research shows that math experiences can take place at home in the beginning of or prior to formal schooling, and can be led by parents. 
Sheri-Lynn Skwarchuk and her colleagues surveyed parents about the frequency of parent-child math activities at home, classifying the experiences as either formal (e.g., doing arithmetic or counting out loud) or informal (e.g., playing card or board games). ${ }^{10}$ Unlike formal math experiences, informal experiences are not meant to explicitly teach math, but do so incidentally through everyday activities, such as play and household tasks. The more frequently parents reported engaging their children in both types of experiences, the better their children's mathematical knowledge fared in first grade.

Observational studies have shown how informal math-related experiences encourage families to explore specific early math concepts during everyday activities. Researchers observed parents and their four-year-olds at home making crispy rice treats by following a recipe. ${ }^{11}$ During the activity, parents and children identified numbers (e.g., number of cups of cereal needed) and counted out loud (e.g., to keep track of the number of cups of cereal added). In fewer instances, they compared quantities and did arithmetic. Opportunities to talk about number concepts also exist during parent-preschooler play with board games such as The Ladybug Game, ${ }^{12}$ number puzzles, ${ }^{13}$ and book reading accompanied by free play with toys related to the story (e.g., cash register, toy food, and play money). ${ }^{14}$ Thus, many playful and regularly occurring informal activities serve as contexts for families to talk about math.

A more recent study demonstrated that math can be explored on tablet computers at home..$^{15}$ Storybook reading at bedtime was swapped with a math activity by inviting families of first graders to solve math problems on an app called Bedtime Math (http://bedtimemath.org). ${ }^{16}$ The app gave families a problem to work on, and children who used the app with their parents earned better math grades in school than those who did not use the app. Many apps are labeled "educational" but do not have the research to support this claim. Librarians can promote research-supported apps such as this one as useful tools for athome math learning.

\section{Why Might Parent-Child Math Experiences Differ?}

To discover why parents' math interactions with their children vary, researchers interviewed mothers of preschoolers, asking for their thoughts about math. ${ }^{17}$ The majority were not confident about their math skills, were more interested in supporting early literacy, thought that math skills were less important than literacy development, and were unsure what math skills their children should be learning. In another study, parents of preschoolers were asked to estimate their children's numerical knowledge, and found that parents were uncertain about their children's abilities to compare two numbers (e.g., determine which is bigger) and do arithmetic, but were more certain about their children's abilities to count and name numbers. ${ }^{18}$ They less frequently supported the skills about which they were less certain. This implies that parents do not support math skills they know less about, and also that parents may hold less-thanpositive attitudes and perceptions about math.

\section{How Can Librarians Help Parents Support Math during Programming?}

The National Association for the Education of Young Children (NAEYC) for Families website (https://families.naeyc.org) offers many helpful tips for parents. Articles include "Five Ways to Build Math into Your Child's Day” (https://families.naeyc.org /learning-and-development/music-math-more/5-ways-buildmath-your-childs-day), "Math Talk with Infants and Toddlers" (https://families.naeyc.org/learning-and-development/musicmath-more/math-talk-infants-and-toddlers), and "Support Math Readiness through Math Talk” (https://families.naeyc.org /learning-and-development/music-math-more/support-math -readiness-through-math-talk). ${ }^{19} \delta$.

\section{References}

1. Alice Klein et al., "Scaling Up an Effective Pre-K Mathematics Intervention: Mediators and Child Outcomes" (paper presented at the Society for Research on Educational Effectiveness Spring 2011 conference, Washington, DC, March 3, 2011).

2. Russell L. Rothman et al., "Perspective: The Role of Numeracy in Health Care," Journal of Health Communication 13, no. 6 (2008): 583-95, http://doi .org/10.1080/10810730802281791.

3. Greg J. Duncan et al., "School Readiness and Later Achievement," Developmental Psychology 43, no. 6 (2007): 1428-46, https://doi.org/10.1037/0012-1649.43.6.1428; Nancy C. Jordan et al., "Early Math Matters: Kindergarten Number Competence and Later Mathematics Outcomes," Developmental Psychology 45, no. 3 (2009): 850-67, https://doi.org/10.1037/a0014939; Tutrang Nguyen et al., "Which Preschool Mathematics Competencies Are Most Predictive of Fifth Grade Achievement?," Early Childhood Research Quarterly 36, 3rd Quarter (2016): 550-60, https:// doi.org/10.1016/j.ecresq.2016.02.003.

4. Talia Berkowitz et al., "Math at Home Adds Up to Achievement in School," Science 350, no. 6257 (2015): 196-98, https://doi.org/10.1126/science.aac7427; Susan C. Levine et al., "What Counts in the Development of Young Children's Number Knowledge?," Developmental Psychology 46, no. 5 (2010): 1309-19, https://doi.org /10.1037/a0019671; Geetha B. Ramani, Robert S. Siegler, and Aline Hitti, "Taking It to the Classroom: Number Board Games as a Small Group Learning Activity," Journal of Educational Psychology 104, no. 3 (2012): 661-72, https://doi.org/10.1037/a0028995.

5. Joanna Cannon and Herbert P. Ginsburg, “'Doing the Math': Maternal Beliefs about Early Mathematics Versus Language Learning," Early Education and Development 19, no. 2 (2008): 238-60, https://doi.org/10.1080/10409280 801963913.

6. Maureen Vandermaas-Peeler et al., "Numeracy-Related Exchanges in Joint Storybook Reading and Play," International Journal of Early Years Education 17, no. 1 
(2009): 67-84, https://doi.org/10.1080/0966976080 2699910.

7. Levine et al., "What Counts in the Development of Young Children's Number Knowledge?"

8. Elizabeth A. Gunderson and Susan C. Levine, "Some Types of Parent Number Talk Count More than Others: Relations between Parents' Input and Children's Cardinal-Number Knowledge," Developmental Science 14, no. 5 (2011): 102132, https://doi.org/10.1111/j.1467-7687.2011.01050.x.

9. Kelly S. Mix et al., "Acquisition of the Cardinal Word Principle: The Role of Input," Early Childhood Research Quarterly 27, no. 2 (2012): 274-83, https:// doi.org/10.1016 /j.ecresq.2011.10.003.

10. Sheri-Lynn Skwarchuk, Carla Sowinski, and Jo-Anne LeFevre, "Formal and Informal Home Learning Activities in Relation to Children's Early Numeracy and Literacy Skills: The Development of a Home Numeracy Model," Journal of Experimental Child Psychology 121 (May 2014): 63-84, https://doi.org/10.1016/j.jecp.2013.11.006.

11. Maureen Vandermaas-Peeler et al., "Parental Support of Numeracy during a Cooking Activity with Four-Year-Olds," International Journal of Early Years Education 20, no. 1 (2012): 78-93, https://doi.org/10.1080/09669760.2012.663 237.

12. Maureen Vandermaas-Peeler and Caroline Pittard, "Influences of Social Context on Parent Guidance and Low-Income Preschoolers' Independent and Guided Math Performance," Early Child Development and Care 184, no. 4 (2014): 500-21, https://doi.org/10.1080/03004430.2013 .799155
13. Geetha B. Ramani et al., "Math Talk during Informal Learning Activities in Head Start Families," Cognitive Development 35 (July-September 2015): 15-33, https:// doi .org/10.1016/j.cogdev.2014.11.002.

14. Vandermaas-Peeler et al., "Numeracy-Related Exchanges in Joint Storybook Reading and Play."

15. Berkowitz et al., "Math at Home Adds Up to Achievement in School."

16. Bedtime Math Foundation, "Bedtime Math," 2015, http:// bedtimemath.org.

17. Cannon and Ginsburg, “'Doing the Math': Maternal Beliefs about Early Mathematics Versus Language Learning.”

18. Erica L. Zippert and Geetha B. Ramani, "Parents' Estimations of Preschoolers' Number Skills Relate to AtHome Number-Related Activity Engagement," Infant and Child Development (2016), https://doi.org/10.1002 /icd.1968.

19. Laura Bilodau Overdeck, "Five Ways to Build Math into Your Child's Day," NAEYC for Families, 2017, https:// families.naeyc.org/learning-and-development/music -math-more/5-ways-build-math-your-childs-day; Jan Greenberg, "Math Talk with Infants and Toddlers," NAEYC for Families, 2017, https://families.naeyc.org/learning -and-development/music-math-more/math-talk-infants -and-toddlers; Eugene Geist, "Support Math Readiness through Math Talk," NAEYC for Families, 2017, http:// families.naeyc.org/learning-and-development/music -math-more/support-math-readiness-through -math-talk.

\section{Index to Advertisers}

Annick Press

...31

ALSC .33, 37

ALSC and ALA Editions
Boyds Mills Press cover 4

NorthSouth Books cover 3 